\title{
Gaseous Reduction Model for Sinter in Consideration of Calcium Ferrite Reaction Process (Unreacted-core Shrinking Model for Six Interfaces)
}

\author{
Tateo USUI, ${ }^{1 *}$ Yasuhiro NAKAMURO, ${ }^{2)}$ Masahiro NISHI, ${ }^{3)}$ Masaaki NAITO, ${ }^{4)}$ Hideki ONO ${ }^{5)}$ and \\ Paulo Santos ASSIS ${ }^{6}$ \\ 1) Joining and Welding Research Institute, Osaka University, 11-1, Mihogaoka, Ibaraki, Osaka, 567-0047 Japan. \\ 2) Formerly Faculty of Engineering, Fukui Univ. of Technology. Now at Naniwa Pump Mfg. Co., Ltd., 3-11-5, Shin-machi, Nishi- \\ ku, Osaka, 550-0013 Japan. $\quad 3$ 3) Formerly Faculty of Engineering, Fukui Univ. of Technology. Now at Izumi Industry, Inc., \\ 85, Machi-oosaka, Shiga-machi, Hakui-gun, Ishikawa, 925-0167 Japan. $\quad 4)$ Nippon Steel \& Sumikin Technology Co., Ltd., \\ 20-1, Shintomi, Futtsu, Chiba, 293-0011 Japan. $\quad$ 5) Graduate School of Engineering, Osaka University, 2-1, Yamadaoka, \\ Suita, Osaka, 565-0871 Japan. $\quad$ 6) School of Mines, Federal University of Ouro Preto / REDEMAT, Praça Tiradentes 20, \\ Ouro Preto, Minas Gerais, 35400-000 Brazil.
}

(Received on February 9, 2015; accepted on April 23, 2015; originally published in Tetsu-to-Hagané, Vol. 100, 2014, No. 2, pp. 294-301)

\begin{abstract}
Reducible oxides containing iron in iron ore sinter are hematite, magnetite and quaternary calcium ferrite (abbreviated by CF), which is the complex crystalline mineral produced from $\mathrm{Fe}_{2} \mathrm{O}_{3}, \mathrm{CaO}, \mathrm{SiO}_{2}$ and $\mathrm{Al}_{2} \mathrm{O}_{3}$. Equilibrium diagram for CF reduction with $\mathrm{CO}-\mathrm{CO}_{2}$ gas mixture is a little but significantly different from the one for pure iron oxides. In previous analyses for reduction reaction of iron oxides in a blast furnace, however, sinter has been treated as pure iron oxides; existence of CF has been ignored. Reduction steps for CF can be written as

$$
\mathrm{CF}\left(={ }^{\circ} \mathrm{Fe}_{2} \mathrm{O}_{3}{ }^{\prime}\right) \rightarrow{ }^{`} \mathrm{Fe}_{3} \mathrm{O}_{4}{ }^{\prime} \rightarrow{ }^{`} \mathrm{FeO} \text { ' } \rightarrow \text { 'Fe', }
$$

which are much the same as pure iron oxides, where ' $\mathrm{Fe}_{2} \mathrm{O}_{3}$ ', ' $\mathrm{Fe}_{3} \mathrm{O}_{4}$ ', ' $\mathrm{FeO}$ ' and ' $\mathrm{Fe}$ ' designate hematite, magnetite, wustite and iron stages of $\mathrm{CF}$, respectively. However, a reported variation of gas composition with temperature measured in a blast furnace shows that the gas composition in the thermal reserve zone is a little higher than the wustite/iron equilibrium, the reduction potential of which is less than that of 'FeO'/Fe' equilibrium and hence 'FeO' cannot be reduced to 'Fe'. In the present work, therefore, gaseous reduction model for sinter is developed in consideration of CF reaction process; unreacted-core shrinking model for six interfaces is proposed to take into account reaction processes of CF as well as pure iron oxides. Trial comparison of the calculated reduction curve with our previously reported experimental data under simulated blast furnace conditions shows rather good agreement.
\end{abstract}

KEY WORDS: ironmaking; blast furnace; sinter; calcium ferrite; gaseous reduction; reaction model; reducing agent control; resources.

\section{Introduction}

As Sugiyama et al. ${ }^{1)}$ reported, quaternary calcium ferrite (abbreviated by $\mathrm{CF}$, afterward) in commercial iron ore sinter takes in $\mathrm{SiO}_{2}$ by considerable amount and makes it harmless, because $\mathrm{SiO}_{2}$ causes to produce very hard-to-be-reduced minerals, ${ }^{2)}$ such as $2 \mathrm{FeO} \cdot \mathrm{SiO}_{2}$ (fayalite) and $\mathrm{CaO} \cdot \mathrm{FeO} \cdot \mathrm{SiO}_{2}$. Also CF is one of the important mineral phases having good reducibility next to iron oxides. Therefore, the evaluation of reduction rate of $\mathrm{CF}$ becomes more and more important, as the quality of raw materials (iron ore) has been deteriorating and, consequently, the content of $\mathrm{SiO}_{2}$ has been increasing. Namely, $\mathrm{CF}$ takes in $\mathrm{SiO}_{2}$ to produce the complex crystal-

\footnotetext{
* Corresponding author: E-mail: usui@mat.eng.osaka-u.ac.jp DOI: http://dx.doi.org/10.2355/isijinternational.ISIJINT-2015-060
}

line mineral composed of $\mathrm{Fe}_{2} \mathrm{O}_{3}, \mathrm{CaO}, \mathrm{SiO}_{2}$ and $\mathrm{Al}_{2} \mathrm{O}_{3}{ }^{1)}$ and therefore the increase of $\mathrm{CF}$ ratio in sinter contributes to the improvement of sinter reducibility through the decrease of hard-to-be-reduced minerals. On the other hand, in order to decrease the ratio of the reducing agent in a blast furnace, trials to decrease the thermal reserve zone temperature have been carried out through the rate enhancement of in-furnace reactions by the close arrangement methods between ore and carbonaceous materials, such as the combination of both highly reactive coke and sinter, and carbon composite iron ore agglomerates. ${ }^{3)}$ In the very thermal reserve zone, the reduction equilibrium for $\mathrm{CF}$ is different from that for iron oxide (see Fig. 1), which cannot be ignored for the appropriate analysis of reduction rate of sinter to evaluate and control the blast furnace process correctly on aiming at the positive consideration of resources and environment. 


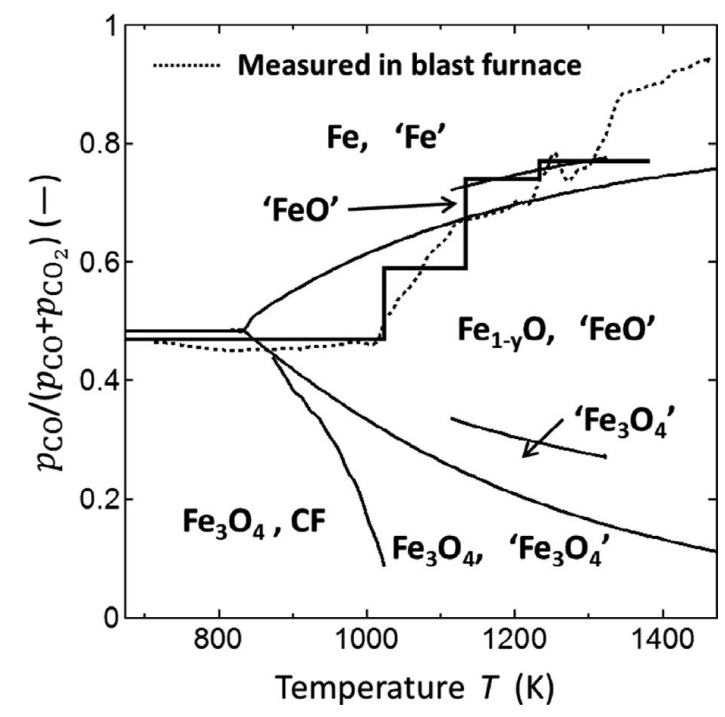

Fig. 1. Equilibrium diagram of iron oxides and quaternary calcium ferrite $(\mathrm{CF})$ reduction with $\mathrm{CO}-\mathrm{CO}_{2}$ gas mixture ${ }^{4)}$ and a variation of gas composition with temperature in a blast furnace. ${ }^{5,6)} \mathrm{CF} /{ }^{\circ} \mathrm{Fe}_{3} \mathrm{O}_{4}$ ' reported by Usui, et al. ${ }^{7)}$ ' $\mathrm{Fe}_{3} \mathrm{O}_{4}{ }^{\prime} / \mathrm{F} \mathrm{FeO}$ ' and ' $\mathrm{FeO}$ '/ $\mathrm{Fe}$ ' reported by Maeda, et al. ${ }^{8,9)}$ Reduction steps of quaternary calcium ferrite: $\mathrm{CF}\left(={ }^{'} \mathrm{Fe}_{2} \mathrm{O}_{3}{ }^{\prime}\right) \rightarrow{ }^{'} \mathrm{Fe}_{3} \mathrm{O}_{4}{ }^{\prime} \rightarrow{ }^{'} \mathrm{FeO}$ ' $\rightarrow{ }^{'} \mathrm{Fe}$ '

where, ' $\mathrm{Fe}_{2} \mathrm{O}_{3}$ ', ' $\mathrm{Fe}_{3} \mathrm{O}_{4}$ ', ' $\mathrm{FeO}$ ' and ' $\mathrm{Fe}$ ' are hematite, magnetite, wustite and iron stages of CF, respectively. Stepwise solid line shows previously reported experimental conditions which simulated blast furnace conditions. ${ }^{10)}$

Sinter is the mixture of iron oxides (hematite and magnetite) and CF. After reconsidering previous analyses for sinter in which the reduction reaction of CF was regarded as those of iron oxides, we have proposed new reduction reaction model on the basis of the unreacted-core shrinking model in the present work. Not only the reduction equilibrium but also the reduction rate for $\mathrm{CF}$ are different from those for iron oxides. By this newly proposed model, rather precise reduction process of sinter in the blast furnace where the sinter is exposed to concurrent variations of the temperature and the gas composition can be taken into account, and hence the effect of CF can be reproduced quantitatively in order to contribute and overcome the problems of resources and environment. Namely, the present work may play a part in constituent researches to direct such a blast furnace with low reducing agent ratio using sinter produced from low grade iron ore, what is called, those for realizing the resources-and-environment-conscious ironmaking process. The appropriateness of the formulated model structure has been tried to verify in part by using the previously reported experimental data ${ }^{10)}$ under the simulated variations of temperature and gas composition in a blast furnace.

\section{Constitution of Gaseous Reduction Model for Sinter}

\subsection{Formulation of Layers and Rate Parameters}

Until now, unreacted-core shrinking models for one interface $^{11)}$ and three interfaces ${ }^{12-14)}$ have been used temporarily to analyze the gaseous reduction rate for sinter. ${ }^{10,15-17)}$ In the present work, the unreacted-core shrinking model has been used and applied as the one for six interfaces. Although the present model is not enough to represent the reaction fashion of sinter, this model makes it possible to include the differences of chemical equilibrium and reaction rate
Table 1. Definition of symbols for chemical reaction rate constant $k_{\mathrm{c}}$ and effective diffusivity $D_{\mathrm{e}}$ in relation to radial coordinate $r$ under the unreacted-core shrinking model for six interfaces in the reduction stages from hematite, magnetite, wustite to iron both for pure iron oxide and quaternary calcium ferrite (CF); the symbols $\mathrm{CFh}, \mathrm{CFm}$, $\mathrm{CFW}$ and $\mathrm{CFf}$ are abbreviations for hematite, magnetite, wustite and iron stages of $\mathrm{CF}$, respectively, whereas $\mathrm{h}, \mathrm{m}$ and $\mathrm{w}$ are those for pure iron oxide.

\begin{tabular}{|c|c|c|c|c|}
\hline \multicolumn{2}{|c|}{$\begin{array}{c}\text { Layer } \\
\text { No. (Phases) }\end{array}$} & $r$ & $k_{\mathrm{c}}$ & $D_{\mathrm{e}}$ \\
\hline (1) & $(\mathrm{h}+\mathrm{CFh})$ & & & - \\
\hline (2) & $(\mathrm{m}+\mathrm{CFh})$ & & & $D_{\mathrm{e}}^{(2)}$ \\
\hline (3) & $(\mathrm{m}+\mathrm{CFm})$ & & & $D_{\mathrm{e}}^{(3)}$ \\
\hline (4) & $(\mathrm{w}+\mathrm{CFm})$ & & & $D_{\mathrm{e}}^{(4)}$ \\
\hline (5) & $(\mathrm{w}+\mathrm{CFw})$ & & & $D_{\mathrm{e}}^{(5)}$ \\
\hline (6) & $(\mathrm{Fe}+\mathrm{CFw})$ & & & $D_{\mathrm{e}}^{(6)}$ \\
\hline (7) & $(\mathrm{Fe}+\mathrm{CFf})$ & & & $D_{\mathrm{e}}^{(7)}$ \\
\hline
\end{tabular}

between iron oxide and CF quantitatively, and therefore, it can represent the most important fundamental characteristics of sinter in the kinetic analysis.

Conceptual illustration of the unreacted-core shrinking model for six interfaces was shown in Ref. 18). As the symbol manipulation to derive equations, hematite, magnetite, wustite and iron along the reduction steps of iron oxide phases are expressed by h, $\mathrm{m}, \mathrm{w}$ and Fe; in a similar way, hematite, magnetite, wustite and iron stages of CF phases are expressed by $\mathrm{CFh}, \mathrm{CFm}, \mathrm{CFw}$ and CFf. Then, the following seven layers are formed in accordance with the reduction equilibrium shown in Fig. 1:

The first layer: $\mathrm{h}+\mathrm{CFh}, \quad$ The second layer: $\mathrm{m}+\mathrm{CFh}$, The third layer: $\mathrm{m}+\mathrm{CFm}$, The fourth layer: $\mathrm{w}+\mathrm{CFm}$,

The fifth layer: $w+C F w$, The sixth layer: $\mathrm{Fe}+\mathrm{CFw}$ and The seventh layer: $\mathrm{Fe}+\mathrm{CFf}$.

Table 1 summarizes the definitions and mutual relations in space among the reaction interface radius $r_{\mathrm{i}}[\mathrm{m}]$ and chemical reaction rate constant $k_{\mathrm{c}}[\mathrm{m} / \mathrm{s}]$ at each layer boundary or interface and intra-particle effective diffusivity $D_{\mathrm{e}}\left[\mathrm{m}^{2} / \mathrm{s}\right]$ in each layer, based on the reaction process and the symbol manipulation to derive equations.

\subsection{Rate Equation for Each Process}

In the present unreacted-core shrinking model for six 
interfaces, the rate equation for each process given below can be written by making reference to the previously reported unreacted-core shrinking model for three interfaces, ${ }^{12-14,17)}$ as follows:

\subsubsection{Diffusion Process in a Gas Film}

The diffusion rate in a gas film, in which the effect of the resistance due to the rate of gas flow ${ }^{17,19)}$ is taken into account, can be written as Eq. (1), where $k_{\mathrm{g}}{ }^{*}$ in $R_{\mathrm{g}}{ }^{*}$ defined by Eq. (2) designates the mass transfer coefficient in a gas film $[\mathrm{m} / \mathrm{s}]$ in consideration of the resistance due to the rate of gas flow and is expressed as Eq. (3).

$$
\begin{array}{r}
n_{\mathrm{COg}}^{*}=-\frac{\left(C_{\mathrm{COb}}-C_{\mathrm{CO}(\mathrm{o})}\right)}{R_{\mathrm{g}}^{*}} \cdots \cdot . \\
R_{\mathrm{g}}^{*}=\frac{1}{\left(4 \pi r \mathrm{o}^{2} k_{\mathrm{g}}^{*}\right)} \cdots \cdots \cdots \cdot \ldots \\
1 / k_{\mathrm{g}}^{*}=1 / k_{g}+\kappa\left(4 \pi r_{0}^{2} / V_{T}\right) . \cdots
\end{array}
$$

Here, $C_{\mathrm{COb}}, C_{\mathrm{CO}(0)}$ : $\mathrm{CO}$ gas concentrations in the bulk gas and at the surface of the sample particle, respectively [mol $\left.\mathrm{CO} / \mathrm{m}^{3}\right], k_{\mathrm{g}}$ : mass transfer coefficient in a gas film $[\mathrm{m} / \mathrm{s}], r_{\mathrm{o}}$ : radius of a sphere having the same volume of the sample particle $[\mathrm{m}], V_{\mathrm{T}}$ : flow rate at the ambient temperature $T$ $\left[\mathrm{m}^{3} / \mathrm{s}\right]$, and $\kappa$ contribution factor for the resistance due to the rate of gas flow $[-]$.

\subsubsection{Diffusion Process in the Particle}

Diffusion rate in the particle for each layer, $n_{\mathrm{COd}}[\mathrm{mol}$ $\mathrm{CO} / \mathrm{s}$ ], can be represented as follows, in which $\mathrm{CO}$ concentration at each layer boundary $r_{\mathrm{i}}$ is expressed by $C_{\mathrm{CO}}[\mathrm{mol}$ $\left.\mathrm{CO} / \mathrm{m}^{3}\right]$ :

$$
\begin{aligned}
& n_{\mathrm{COd}}^{(2)}=-\frac{\left(C_{\mathrm{COi}}^{(2 / 3)}-C_{\mathrm{COi}}^{(1 / 2)}\right)}{R_{\mathrm{d}}^{(\mathrm{m}, \mathrm{CFh})}} \\
& R_{\mathrm{d}}^{(\mathrm{m}, \mathrm{CFh})}=\frac{\left(\frac{1}{r_{\mathrm{i}}^{(1 / 2)}}-\frac{1}{r_{\mathrm{i}}^{(2 / 3)}}\right)}{4 \pi D_{\mathrm{e}}^{(2)}} \\
& n_{\mathrm{COd}}^{(3)}=-\frac{\left(C_{\mathrm{COi}}^{(3 / 4)}-C_{\mathrm{COi}}^{(2 / 3)}\right)}{R_{\mathrm{d}}^{(\mathrm{m}, \mathrm{CFm})}} \\
& R_{\mathrm{d}}^{(\mathrm{m}, \mathrm{CFm})}=\frac{\left(\frac{1}{r_{\mathrm{i}}^{(2 / 3)}}-\frac{1}{r_{\mathrm{i}}^{(3 / 4)}}\right)}{4 \pi D_{\mathrm{e}}^{(3)}} \\
& n_{\mathrm{COd}}^{(4)}=-\frac{\left(C_{\mathrm{COi}}^{(4 / 5)}-C_{\mathrm{COi}}^{(3 / 4)}\right)}{R_{\mathrm{d}}^{(\mathrm{w}, \mathrm{CFm})}} \\
& R_{\mathrm{d}}^{(\mathrm{w}, \mathrm{CFm})}=\frac{\left(\frac{1}{r_{\mathrm{i}}^{(3 / 4)}}-\frac{1}{r_{\mathrm{i}}^{(4 / 5)}}\right)}{4 \pi D_{\mathrm{e}}^{(4)}} \\
& n_{\mathrm{COd}}^{(5)}=-\frac{\left(C_{\mathrm{COi}}^{(5 / 6)}-C_{\mathrm{COi}}^{(4 / 5)}\right)}{R_{\mathrm{d}}^{(\mathrm{w}, \mathrm{CFw})}}
\end{aligned}
$$




$$
\begin{gathered}
R_{\mathrm{c}}^{(\mathrm{w} / \mathrm{Fe})}=\frac{1}{\left\{4 \pi\left(r_{\mathrm{i}}^{(5 / 6)}\right)^{2} k_{\mathrm{C}}^{(\mathrm{w} / \mathrm{Fe})}\left(1+1 / K^{(\mathrm{w} / \mathrm{Fe})}\right)\right\}} \cdots \\
R_{\mathrm{c}}^{(\mathrm{CFw} / \mathrm{CFf})}=\frac{1}{\left\{4 \pi\left(r_{\mathrm{i}}^{(6 / 7)}\right)^{2} k_{\mathrm{C}}^{(\mathrm{CFw} / \mathrm{CFf})}\left(1+\frac{1}{\left.K^{(\mathrm{CFw} / \mathrm{CFf})}\right)}\right)\right\}} \cdots \cdots \cdots
\end{gathered}
$$

Here, $C_{\mathrm{COe}}$ : equilibrium concentration of $\mathrm{CO}\left[\mathrm{mol} \mathrm{CO} / \mathrm{m}^{3}\right]$ and $K$ : equilibrium constant $[-]$.

\subsection{Relationships among These Rates ${ }^{12-14,17)}$}

Relationships among the rates shown above can be derived by seeing Table 1 and the conceptual figure for the present unreacted-core shrinking model for six interfaces, given in Ref. 18). Overall reaction rate, $n_{\mathrm{CO}}[\mathrm{mol} \mathrm{CO} / \mathrm{s}]$, diffusion rate in a gas film, in which the effect of the resistance due to the rate of gas flow is taken into account, $n_{\mathrm{COg}}^{*}$ and diffusion rate through the 7 th layer $n_{\mathrm{COd}}^{(7)}$ should have the same value with each other under steady state. After CO gas diffuses through the 7th layer, at the reaction interface $\mathrm{CFw} /$ CFf, $r_{\mathrm{i}}^{(6 / 7)}$, CO gas is divided into the one consumed by the reduction reaction from $\mathrm{CFw}$ to $\mathrm{CFf}$ and the one diffusing through the 6th layer. These relations can be expressed as Eq. (28). After CO gas diffuses through the 6th layer, at the reaction interface wustite/iron, $r_{\mathrm{i}}^{(5 / 6)}$, it is divided into the one consumed by the reduction reaction from wustite to iron and the one diffusing through the 5th layer. This relation can be given by Eq. (29). The following steps are similar to the above-mentioned and Eqs. (30)-(32) can be derived. Finally, after CO gas diffuses through the 2nd layer, it is consumed by the reduction reaction from hematite to magnetite at the reaction interface hematite/magnetite, $r_{\mathrm{i}}^{(1 / 2)}$, which can be written by Eq. (33).

$$
\begin{aligned}
& n_{\mathrm{CO}}=n_{\mathrm{COg}}^{*}=n_{\mathrm{COd}}^{(7)}=n_{\mathrm{COc}}^{(\mathrm{CFw} / \mathrm{CFf})}+n_{\mathrm{COd}}^{(6)} \\
& n_{\mathrm{COd}}^{(6)}=n_{\mathrm{COc}}^{(\mathrm{w} / \mathrm{Fe})}+n_{\mathrm{COd}}^{(5)} \\
& n_{\mathrm{COd}}^{(5)}=n_{\mathrm{COc}}^{(\mathrm{CFm} / \mathrm{CFw})}+n_{\mathrm{COd}}^{(4)} \\
& n_{\mathrm{COd}}^{(4)}=n_{\mathrm{COc}}^{(\mathrm{m} / \mathrm{w})}+n_{\mathrm{COd}}^{(3)} \\
& n_{\mathrm{COd}}^{(3)}=n_{\mathrm{COc}}^{(\mathrm{CFh} / \mathrm{CFm})}+n_{\mathrm{COd}}^{(2)} \\
& n_{\mathrm{COd}}^{(2)}=n_{\mathrm{COc}}^{(\mathrm{h} / \mathrm{m})}
\end{aligned}
$$

\subsection{Derivation of Expression for Overall Reaction Rate $^{12-14,17)}$}

From the above-shown rate equations and relations, the expression for the overall reaction rate can be derived by eliminating unknown variables, $\mathrm{CO}$ concentrations at six interfaces and the surface, $C_{\mathrm{CO}}$ i and $C_{\mathrm{CO}(0)}$, in order.

The CO concentration at $r_{\mathrm{i}}{ }^{(1 / 2)}, C_{\mathrm{COi}}^{(1 / 2)}$, can be eliminated by using Eqs. (4), (16) and (33), and the diffusion rate $n_{\mathrm{COd}}^{(2)}$ can be derived as follows:

$$
n_{\mathrm{COd}}^{(2)}=\frac{-C_{\mathrm{COi}}^{(2 / 3)}+C_{\mathrm{COe}}^{(\mathrm{h} / \mathrm{m})}}{R_{\mathrm{d}}^{(\mathrm{m}, \mathrm{CFh})}+R_{\mathrm{c}}^{(\mathrm{h} / \mathrm{m})}}
$$

Then, the $\mathrm{CO}$ concentration at $r_{\mathrm{i}}^{(2 / 3)}, C_{\mathrm{CO}}^{(2 / 3)}$, can be eliminated by inserting Eqs. (6), (18) and (34) into Eq. (32), and the diffusion rate $n_{\mathrm{COd}}^{(3)}$ can be derived as follows:

in which

$$
n_{\mathrm{COd}}^{(3)}=\frac{-C_{\mathrm{COi}}^{(3 / 4)} \Lambda_{1}+\Lambda_{2}}{R_{\mathrm{d}}^{(\mathrm{m}, \mathrm{CFm})} \Lambda_{1}+1}
$$

$$
\begin{aligned}
& \Lambda_{1}=\frac{1}{R_{\mathrm{d}}^{(\mathrm{m}, \mathrm{CFh})}+R_{\mathrm{C}}^{(\mathrm{h} / \mathrm{m})}}+\frac{1}{R_{\mathrm{C}}^{(\mathrm{CFh} / \mathrm{CFm})}} \\
& \Lambda_{2}=\frac{C_{\mathrm{COe}}^{(\mathrm{h} / \mathrm{m})}}{R_{\mathrm{d}}^{(\mathrm{m}, \mathrm{CFh})}+R_{\mathrm{C}}^{(\mathrm{h} / \mathrm{m})}}+\frac{C_{\mathrm{COe}}^{(\mathrm{CFh} / \mathrm{CFm})}}{R_{\mathrm{C}}^{(\mathrm{CFh} / \mathrm{CFm})}}
\end{aligned}
$$

Similarly, $n_{\text {COd }}^{(4)}$ can be derived by inserting Eqs. (8), (20) and (35) into Eq. (31) and eliminating $C_{\mathrm{COi}}^{(3 / 4)}$, then

$$
n_{\mathrm{COd}}^{(4)}=\frac{-C_{\mathrm{COi}}^{(4 / 5)} \Lambda_{3}+\Lambda_{4}}{R_{\mathrm{d}}^{(\mathrm{w}, \mathrm{CFm})} \Lambda_{3}+1}
$$

where,

$$
\begin{aligned}
& \Lambda_{3}=\frac{\Lambda_{1}}{R_{\mathrm{d}}^{(\mathrm{m}, \mathrm{CFm})} \Lambda_{1}+1}+\frac{1}{R_{\mathrm{C}}^{(\mathrm{m} / \mathrm{w})}} \\
& \Lambda_{4}=\frac{\Lambda_{2}}{R_{\mathrm{d}}^{(\mathrm{m}, \mathrm{CFm})} \Lambda_{1}+1}+\frac{C_{\mathrm{COe}}^{(\mathrm{m} / \mathrm{w})}}{R_{\mathrm{C}}^{(\mathrm{m} / \mathrm{w})}}
\end{aligned}
$$

Insertion of Eqs. (10), (22) and (38) into Eq. (30) and eliminating $C_{\mathrm{COi}}^{(4 / 5)}$ yield

$$
n_{\mathrm{COd}}^{(5)}=\frac{-C_{\mathrm{COi}}^{(5 / 6)} \Lambda_{5}+\Lambda_{6}}{R_{\mathrm{d}}^{(\mathrm{w}, \mathrm{CFw})} \Lambda_{5}+1}
$$

where,

$$
\begin{aligned}
& \Lambda_{5}=\frac{\Lambda_{3}}{R_{\mathrm{d}}^{(\mathrm{w}, \mathrm{CFm})} \Lambda_{3}+1}+\frac{1}{R_{\mathrm{C}}^{(\mathrm{CFm} / \mathrm{CFw})}} \\
& \Lambda_{6}=\frac{\Lambda_{4}}{R_{\mathrm{d}}^{(\mathrm{w}, \mathrm{CFm})} \Lambda_{3}+1}+\frac{C_{\mathrm{COe}}^{(\mathrm{CFm} / \mathrm{CFw})}}{R_{\mathrm{C}}^{(\mathrm{CFm} / \mathrm{CFw})}}
\end{aligned}
$$

Insertion of Eqs. (12), (24) and (41) into Eq. (29) and eliminating $C_{\mathrm{COi}}^{(5 / 6)}$ give

$$
n_{\mathrm{COd}}^{(6)}=\frac{-C_{\mathrm{COi}}^{(6 / 7)} \Lambda_{7}+\Lambda_{8}}{R_{\mathrm{d}}^{(\mathrm{Fe}, \mathrm{CFw})} \Lambda_{7}+1}
$$

where,

$$
\begin{aligned}
& \Lambda_{7}=\frac{\Lambda_{5}}{R_{\mathrm{d}}^{(\mathrm{w}, \mathrm{CFw})} \Lambda_{5}+1}+\frac{1}{R_{\mathrm{C}}^{(\mathrm{w} / \mathrm{Fe})}} \\
& \Lambda_{8}=\frac{\Lambda_{6}}{R_{\mathrm{d}}^{(\mathrm{w}, \mathrm{CFw})} \Lambda_{5}+1}+\frac{C_{\mathrm{COe}}^{(\mathrm{w} / \mathrm{Fe})}}{R_{\mathrm{C}}^{(\mathrm{w} / \mathrm{Fe})}}
\end{aligned}
$$

Insertion of Eqs. (14), (26) and (44) into the latter part of Eq. (28), $n_{\mathrm{COd}}^{(7)}=n_{\mathrm{COc}}^{(\mathrm{CFw} / \mathrm{CFf})}+n_{\mathrm{COd}}^{(6)}$, and eliminating $C_{\mathrm{COi}}^{(6 / 7)}$ lead to 


$$
n_{\mathrm{COd}}^{(7)}=\frac{-C_{\mathrm{CO}(\mathrm{o})} \Lambda_{9}+\Lambda_{10}}{R_{\mathrm{d}}^{(\mathrm{Fe}, \mathrm{CFf})} \Lambda_{9}+1}
$$

in which,

$$
\begin{aligned}
& \Lambda_{9}=\frac{\Lambda_{7}}{R_{\mathrm{d}}^{(\mathrm{Fe}, \mathrm{CFw})} \Lambda_{7}+1}+\frac{1}{R_{\mathrm{C}}^{(\mathrm{CFw} / \mathrm{CFf})}} \\
& \Lambda_{10}=\frac{\Lambda_{8}}{R_{\mathrm{d}}^{(\mathrm{Fe}, \mathrm{CFw})} \Lambda_{7}+1}+\frac{C_{\mathrm{COe}}^{(\mathrm{CFw} / \mathrm{CFf})}}{R_{\mathrm{C}}^{(\mathrm{CFw} / \mathrm{CFf})}}
\end{aligned}
$$

Finally, the following expression for the overall reaction rate can be derived by inserting Eqs. (1) and (47) into the former part of Eq. (28), $n_{\mathrm{CO}}=n_{\mathrm{COg}}^{*}=n_{\mathrm{COd}}^{(7)}$, and eliminating $C_{\mathrm{CO}(\mathrm{o})}$ :

$$
n_{\mathrm{CO}}=-\frac{\left(C_{\mathrm{COb}} \Lambda_{9}-\Lambda_{10}\right)}{\Lambda_{9}\left(R_{\mathrm{d}}^{(\mathrm{Fe}, \mathrm{CFf})}+R_{\mathrm{g}}^{*}\right)+1}
$$

\subsection{Expression for Fractional Reduction ${ }^{12-14,17)}$}

The calculation procedure to obtain the fractional reduction at each time is explained here. In the first place, by calculating Eqs. (28) through (33) in the opposite procedure to the derivation of Eq. (50), the $\mathrm{CO}$ concentration at each interface $C_{\mathrm{CO} \text { i }}$ can be written as follows:

The $\mathrm{CO}$ concentration at the surface, $C_{\mathrm{CO}(0)}$, can be eliminated by inserting Eqs. (1) and (14) into the former part of Eq. (28) and then the CO concentration at the interface $r_{\mathrm{i}}{ }^{(6 / 7)}$, $C_{\mathrm{COi}}^{(6 / 7)}$, can be expressed by using $C_{\mathrm{COb}}, R_{\mathrm{g}}^{*}, R_{\mathrm{d}}^{(\mathrm{Fe}, \mathrm{CFf})}$ and $n_{\mathrm{CO}}$, as follows:

$$
C_{\mathrm{COi}}^{(6 / 7)}=n_{\mathrm{CO}}\left(R_{\mathrm{d}}^{(\mathrm{Fe}, \mathrm{CFf})}+R_{\mathrm{g}}^{*}\right)+C_{\mathrm{COb}}
$$

in which, both $C_{\mathrm{COb}}$ and $R_{\mathrm{g}}^{*}$ are constants depending on the experimental conditions, while $R_{\mathrm{d}}^{(\mathrm{Fe}, \mathrm{CFf})}$ expressed by Eq. (15) and $n_{\text {CO }}$ written by Eq. (50) include unknown interface radii $r_{\mathrm{i}}$ as well as rate parameters, namely, chemical reaction rate constant $k_{\mathrm{c}}$ and intra-particle effective diffusivity $D_{\mathrm{e}}$.

Next, $C_{\mathrm{COi}}^{(5 / 6)}$ can be written by applying Eq. (51) to the latter part of Eq. (28) as

$$
C_{\mathrm{COi}}^{(5 / 6)}=R_{\mathrm{d}}^{(\mathrm{Fe}, \mathrm{CFw})}\left(n_{\mathrm{CO}}-\frac{-C_{\mathrm{COi}}^{(6 / 7)}+C_{\mathrm{COe}}^{(\mathrm{CFw} / \mathrm{CFf})}}{R_{\mathrm{C}}^{(\mathrm{CFw} / \mathrm{CFf})}}\right)+C_{\mathrm{COi}}^{(6 / 7)} \ldots
$$

Similarly, CO concentration at each interface $C_{\mathrm{COi}}^{(\mathrm{s} / \mathrm{t})}(\mathrm{s} / \mathrm{t}=$ $4 / 5,3 / 4,2 / 3$ and $1 / 2$ ) can be written one by one in order, as follows:

$$
\begin{aligned}
& C_{\mathrm{COi}}^{(4 / 5)}=R_{\mathrm{d}}^{(\mathrm{w}, \mathrm{CFw})}\left(\frac{-C_{\mathrm{COi}}^{(6 / 7)}+C_{\mathrm{COi}}^{(5 / 6)}}{R_{\mathrm{d}}^{(\mathrm{Fe}, \mathrm{CFw})}}-\frac{-C_{\mathrm{COi}}^{(5 / 6)}+C_{\mathrm{COe}}^{(\mathrm{w} / \mathrm{Fe})}}{R_{\mathrm{C}}^{(\mathrm{w} / \mathrm{Fe})}}\right) \\
& +C_{\mathrm{COi}}^{(5 / 6)} \\
& C_{\mathrm{COi}}^{(3 / 4)}=R_{\mathrm{d}}^{(\mathrm{w}, \mathrm{CFm})}\left(\frac{-C_{\mathrm{COi}}^{(5 / 6)}+\mathrm{C}_{\mathrm{COi}}^{(4 / 5)}}{R_{\mathrm{d}}^{(\mathrm{w}, \mathrm{CFw})}}-\frac{-C_{\mathrm{COi}}^{(4 / 5)}+C_{\mathrm{COe}}^{(\mathrm{CFm} / \mathrm{CFw})}}{R_{\mathrm{C}}^{(\mathrm{CFm} / \mathrm{CFw})}}\right) \\
& +C_{\mathrm{COi}}^{(4 / 5)}
\end{aligned}
$$

$$
\begin{aligned}
& C_{\mathrm{COi}}^{(2 / 3)}=R_{\mathrm{d}}^{(\mathrm{m}, \mathrm{CFm})}\left(\frac{-C_{\mathrm{COi}}^{(4 / 5)}+C_{\mathrm{COi}}^{(3 / 4)}}{R_{\mathrm{d}}^{(\mathrm{w}, \mathrm{CFm})}}-\frac{-C_{\mathrm{COi}}^{(3 / 4)}+C_{\mathrm{COe}}^{(\mathrm{m} / \mathrm{w})}}{R_{\mathrm{C}}^{(\mathrm{m} / \mathrm{w})}}\right) \\
& +C_{\mathrm{COi}}^{(3 / 4)} \\
& C_{\mathrm{COi}}^{(1 / 2)}=R_{\mathrm{d}}^{(\mathrm{m}, \mathrm{CFh})}\left(\frac{-C_{\mathrm{COi}}^{(3 / 4)}+C_{\mathrm{COi}}^{(2 / 3)}}{R_{\mathrm{d}}^{(\mathrm{m}, \mathrm{CFm})}}-\frac{-C_{\mathrm{COi}}^{(2 / 3)}+C_{\mathrm{COe}}^{(\mathrm{CFh} / \mathrm{CFm})}}{R_{\mathrm{C}}^{(\mathrm{CFh} / \mathrm{CFm})}}\right) \\
& +C_{\mathrm{COi}}^{(2 / 3)}
\end{aligned}
$$

For example, at the interface between the 1st layer and the 2nd layer, the mass balance equation between the variations of reduced oxygen in solid phase due to the interface movement and oxygen in gas phase based on the chemical reaction can be expressed in the primitive manner as follows:

$$
\begin{aligned}
& \frac{4}{3} \pi\left(\rho_{\mathrm{O}}^{(\mathrm{h})}-\rho_{\mathrm{O}}^{(\mathrm{Hm})}\right) \frac{d\left(r_{\mathrm{i}}^{(1 / 2)}\right)^{3}}{d t}= \\
& -4 \pi\left(r_{\mathrm{i}}^{(1 / 2)}\right)^{2} k_{\mathrm{C}}^{(\mathrm{h} / \mathrm{m})}\left(1+\frac{1}{K^{(\mathrm{h} / \mathrm{m})}}\right)\left(C_{\mathrm{COi}}^{(1 / 2)}-C_{\mathrm{COe}}^{(\mathrm{h} / \mathrm{m})}\right) \ldots
\end{aligned}
$$

or

$$
\frac{d r_{\mathrm{i}}^{(1 / 2)}}{d t}=-\frac{k_{\mathrm{C}}^{(\mathrm{h} / \mathrm{m})}}{\rho_{\mathrm{O}}^{(\mathrm{h})}-\rho_{\mathrm{O}}^{(\mathrm{Hm})}}\left(1+\frac{1}{K^{(\mathrm{h} / \mathrm{m})}}\right)\left(C_{\mathrm{COi}}^{(1 / 2)}-C_{\mathrm{COe}}^{(\mathrm{h} / \mathrm{m})}\right) \cdots
$$

Similar equations can be obtained for the other interfaces. From the finite difference approximation to the left side of Eq. (58), the relation between the reduction time $t[\mathrm{~s}]$ and the interface radius $r_{\mathrm{i}}^{(1 / 2)}$ can be written by

$$
\frac{d r_{\mathrm{i}}^{(1 / 2)}}{d t} \fallingdotseq \frac{r_{\mathrm{i}}^{(1 / 2)}(\mathrm{k}+1)-r_{\mathrm{i}}^{(1 / 2)}(\mathrm{k})}{\Delta t}
$$

where, $\mathrm{k}$ : time step and $\Delta t$ : time increment [s]. Combination of Eqs. (58) and (59) yields

$$
\begin{aligned}
& r_{\mathrm{i}}^{(1 / 2)}(\mathrm{k}+1)= \\
& r_{\mathrm{i}}^{(1 / 2)}(\mathrm{k})-\frac{k_{\mathrm{C}}^{(\mathrm{h} / \mathrm{m})}}{\rho_{\mathrm{O}}^{(\mathrm{h})}-\rho_{\mathrm{O}}^{(\mathrm{Hm})}}\left(1+\frac{1}{K^{(\mathrm{h} / \mathrm{m})}}\right)\left(C_{\mathrm{COi}}^{(1 / 2)}-C_{\mathrm{COe}}^{(\mathrm{h} / \mathrm{m})}\right) \Delta t . .
\end{aligned}
$$

Then, the value of overall reaction rate $n_{\mathrm{CO}}$ is calculated by Eq. (50) under various initial values given properly, and the values of $C_{\mathrm{COi}}^{(\mathrm{s} / \mathrm{t})}(\mathrm{s} / \mathrm{t}=6 / 7,5 / 6,4 / 5,3 / 4,2 / 3$ and $1 / 2)$ are evaluated by Eqs. (51) through (56). After that, each interface radius, $r_{\mathrm{i}}$, at every time step can be computed one by one in turn by using Eq. (60), for example. The fractional reduction $F[-]$ at each reduction time can be expressed as Eq. (61), in which, $\rho_{\mathrm{O}}$ designates the apparent molar density of reducible oxygen $\left[\mathrm{mol} \mathrm{O} /\left(\operatorname{sinter}-\mathrm{cm}^{3}\right)\right]$; in detail, $\rho_{\mathrm{O}}{ }^{(\mathrm{Hm})}$ represents the one for magnetite reduced from hematite, while $\rho_{\mathrm{O}}{ }^{(\mathrm{Im})}$ shows the one for the initial magnetite in the sinter product (see Table 2). Therefore, the apparent molar density of reducible oxygen from magnetite stage is written as $\rho_{\mathrm{O}}{ }^{(\mathrm{Tm})}$, where $\rho_{\mathrm{O}}{ }^{(\mathrm{Tm})}=\rho_{\mathrm{O}}{ }^{(\mathrm{Hm})}+\rho_{\mathrm{O}}{ }^{(\mathrm{Im})}$. Formally, $\rho_{\mathrm{O}}{ }^{(\mathrm{Fe})}$ and $\rho_{\mathrm{O}}{ }^{(\mathrm{CFf})}$ appear in Eq. (61), but $\rho_{\mathrm{O}}{ }^{(\mathrm{Fe})}=\rho_{\mathrm{O}}{ }^{(\mathrm{CFf})}=0$. 
Table 2. Chemical analysis and physical properties of the sinter reported. ${ }^{10,15,16)}$

\begin{tabular}{|c|c|c|c|c|c|c|c|c|c|c|c|c|}
\hline \multicolumn{13}{|c|}{ Chemical analysis (mass\%) } \\
\hline Sinter & T.Fe & $\mathrm{FeO}$ & $\mathrm{CaO}$ & $\mathrm{SiO}_{2}$ & $\mathrm{Al}_{2} \mathrm{O}_{3}$ & $\mathrm{MgO}$ & $\mathrm{MnO}$ & $\mathrm{TiO}_{2}$ & $\mathrm{P}_{2} \mathrm{O}_{5}$ & $\left(\mathrm{Fe}_{2} \mathrm{O}_{3}\right)$ & $\left(\mathrm{Fe}_{3} \mathrm{O}_{4}\right)$ & $(\mathrm{FeO})$ \\
\hline $\mathrm{A}$ & 57.08 & 5.07 & 8.78 & 5.46 & 1.91 & 1.37 & 0.83 & 0.36 & 0.102 & $(65.84)$ & $(14.71)$ & $(0.507)$ \\
\hline B & 56.95 & 6.11 & 9.25 & 5.33 & 1.97 & 1.40 & 0.31 & 0.68 & 0.123 & $(62.44)$ & $(17.72)$ & $(0.611)$ \\
\hline
\end{tabular}

$$
\left[\begin{array}{c}
{\left[\left(\rho_{\mathrm{O}}^{(\mathrm{h})}-\rho_{\mathrm{O}}^{(\mathrm{Hm})}\right)\left\{r_{\mathrm{O}}^{3}-\left(r_{\mathrm{i}}^{(1 / 2)}\right)^{3}\right\}\right]} \\
+\left[\left(\rho_{\mathrm{O}}^{(\mathrm{Tm})}-\rho_{\mathrm{O}}^{(\mathrm{w})}\right)\left\{r_{\mathrm{O}}^{3}-\left(r_{\mathrm{i}}^{(3 / 4)}\right)^{3}\right\}\right] \\
+\left[\left(\rho_{\mathrm{O}}^{(\mathrm{w})}-\rho_{\mathrm{O}}^{(\mathrm{Fe})}\right)\left\{r_{\mathrm{O}}^{3}-\left(r_{\mathrm{i}}^{(5 / 6)}\right)^{3}\right\}\right] \\
+\left[\left(\rho_{\mathrm{O}}^{(\mathrm{CFh})}-\rho_{\mathrm{O}}^{(\mathrm{CFm})}\right)\left\{r_{\mathrm{O}}^{3}-\left(r_{\mathrm{i}}^{(2 / 3)}\right)^{3}\right\}\right] \\
+\left[\left(\rho_{\mathrm{O}}^{(\mathrm{CFm})}-\rho_{\mathrm{O}}^{(\mathrm{CFw})}\right)\left\{r_{\mathrm{O}}^{3}-\left(r_{\mathrm{i}}^{(4 / 5)}\right)^{3}\right\}\right] \\
+\left[\left(\rho_{\mathrm{O}}^{(\mathrm{CFw})}-\rho_{\mathrm{O}}^{(\mathrm{CFF})}\right)\left\{r_{\mathrm{O}}^{3}-\left(r_{\mathrm{i}}^{(6 / 7)}\right)^{3}\right\}\right]
\end{array}\right]
$$

\section{Evaluation Method of Various Physical Properties Based on Previous Data}

\subsection{Various Constants on Gas Phase}

In the first place, the contribution factor for the resistance due to the rate of gas flow, $\kappa$, can be given by 0.5 at flow rates not so low ${ }^{17,19)}$ in order to evaluate the mass transfer coefficient in a gas film in consideration of the resistance due to the rate of gas flow, $k_{\mathrm{g}}{ }^{*}$. The mass transfer coefficient in a gas film for sinter, $k_{\mathrm{g}}$, can be calculated by semi-theoretical and semi-empirical correlation equation. ${ }^{17,21)}$ Viscosity and diffusion coefficients necessary to calculate the value of $k_{\mathrm{g}}$ from the correlation equation are also shown in the review 17) with the original references.

\subsection{Equilibrium Constants and Equilibrium Concen- trations}

Equilibrium constants of all the reduction steps for iron oxide and those of the reduction steps in ' $\mathrm{Fe}_{3} \mathrm{O}_{4}$ ' $\rightarrow$ ' $\mathrm{FeO}$ ' and ' $\mathrm{FeO}$ ' $\rightarrow$ ' $\mathrm{Fe}$ ' for quaternary calcium ferrite, $\mathrm{CF}$, are summarized in the review 17) with the original references. Equilibrium concentrations can be calculated by these equilibrium constants. However, there is no literature about the equilibrium constant of the reduction step in $\mathrm{CF}$ $\left(={ }^{\prime} \mathrm{Fe}_{2} \mathrm{O}_{3}{ }^{\prime}\right) \rightarrow{ }^{'} \mathrm{Fe}_{3} \mathrm{O}_{4}$ ', but only the literature about "the empirical equation relating temperature and gas composition at equilibrium" reported by one of the present authors and others. ${ }^{7)}$ From this report, the equilibrium constant and equilibrium concentration in this reduction step can be calculated. Equilibrium diagram as well as the nomenclature of ' $\mathrm{Fe}_{2} \mathrm{O}_{3}$ ', ' $\mathrm{Fe}_{3} \mathrm{O}_{4}$ ', ' $\mathrm{FeO}$ ' and ' $\mathrm{Fe}$ ' are shown in Fig. 1 and its caption.

\subsection{Apparent Molar Density of Reducible Oxygen}

Evaluation method for apparent molar density of reducible oxygen is exemplified as follows: Table 2 shows chemical analysis and physical properties of the commercial sinter used in previous experiments. ${ }^{10,15,16)}$ Under the assumption that $90 \%$ of $\mathrm{FeO}$ exists in $\mathrm{Fe}_{3} \mathrm{O}_{4}$ and the rest $10 \%$ in slag, ${ }^{20,21)}$ T.Fe can be divided among $\left(\mathrm{Fe}_{2} \mathrm{O}_{3}\right),\left(\mathrm{Fe}_{3} \mathrm{O}_{4}\right)$ and (FeO), as exemplified in Table 2. In the case of Sinter A, the initial magnetite in the sinter product, Im, is evaluated as 14.71 mass $\%$ and moreover $\left(\mathrm{Fe}_{2} \mathrm{O}_{3}\right)=65.84$ mass $\%$ can be divided between hematite $(\% \mathrm{~h})$ and $\mathrm{Fe}_{2} \mathrm{O}_{3}$ contained in $\mathrm{CF}(\% \mathrm{x})$, namely, $\% \mathrm{~h}+\% \mathrm{x}=65.84$. From the evaluation based on EPMA quantitative analyses reported previously, ${ }^{22)}$ mass ratio of $\mathrm{Fe}_{2} \mathrm{O}_{3}$ in $\mathrm{CF}$ was obtained as 0.693 , and mass ratio of $(\mathrm{h}+\mathrm{Im})$ : $\mathrm{CF}$ can be observed as 0.74:0.26 by using the triangle figure ${ }^{22)}$ among mass ratios of $\mathrm{h}, \mathrm{m}$ and $\mathrm{CF}$ quantitatively determined by the X-ray diffraction internal standard method. From these relations, the apparent molar density of reducible oxygen $\rho_{\mathrm{O}}$ at each reduction step can be calculated.

\section{Discussion and Future Subjects}

In previous works, ${ }^{10,15,16)}$ rate parameters in the unreactedcore shrinking model for three interfaces, three $k_{\mathrm{c}}$ values and three $D_{\mathrm{e}}$ values, were obtained by using single particle and packed bed experimental results on isothermal reduction of Sinter A and B shown in Table 2 by $\mathrm{CO}-\mathrm{CO}_{2}-\mathrm{N}_{2}$ gas mixture on the basis of the unreacted-core shrinking model for one interface in the case of stepwise reduction and the unreacted-core shrinking model for three interfaces in the case of continuous reduction. In order to determine the rate parameters in the present unreacted-core shrinking model for six interfaces, namely, six $k_{\mathrm{c}}$ values and six $D_{\mathrm{e}}$ values, new experiments, for instance, stepwise reduction experiments in six steps are needed; this will be one of the future subjects. Concretely, in the case of such a reduction temperature as all the phases appear, the following stepwise reduction experiments should be done by regulating the concentrations of reducing gas toward a single sample:

$$
\begin{array}{ll}
\mathrm{h} \rightarrow \mathrm{m}, & \mathrm{CFh} \rightarrow \mathrm{CFm}, \quad \mathrm{m} \rightarrow \mathrm{w}, \\
\mathrm{CFm} \rightarrow \mathrm{CFw}, \quad \mathrm{w} \rightarrow \mathrm{Fe}, & \mathrm{CFw} \rightarrow \mathrm{CFf}
\end{array}
$$

Then, chemical reaction rate constant $k_{\mathrm{c}}$ and intra-particle effective diffusivity $D_{\mathrm{e}}$ for each reduction step can be determined by the mixed-control-plot method ${ }^{23)}$ using each experimental data, namely, reduction curve. In the next section, inspection of the present model has been tried in part by using up-rising temperature reduction data of Sinter B packed bed under the stepwise solid line for temperature vs. gas composition ${ }^{10)}$ (see Fig. 1) which roughly simulates the blast furnace conditions. ${ }^{5,6)}$ 
In section $3 \cdot 3$ for apparent molar density of reducible oxygen, the evaluation is exemplified on the basis of both EPMA and XRD analyses reported previously. ${ }^{22)}$ In this EPMA quantitative analysis, columnar shape CF was chosen partly because wider uniform area could be obtained and partly because main part of CF was columnar shape. Therefore, this EPMA quantitative analysis data are considered to be affected by the composition difference due to the structure difference. This is the future subject, but in order to solve this problem exactly, EPMA quantitative analysis to each structure should be carried out and weighted mean value should be calculated by using the ratio of each structure present. This way will lead to improve the accuracy in mass ratio of $\mathrm{Fe}_{2} \mathrm{O}_{3}$ in $\mathrm{CF}$, although EPMA quantitative analysis to fine structure of CF is very difficult. However, in the case of the X-ray diffraction internal standard method to determine the mass ratios of $\mathrm{h}, \mathrm{m}$ and $\mathrm{CF}$ quantitatively, the peak position for $\mathrm{CF}$ is the same irrespective of the structure and therefore, handling to obtain the weighted mean value is not necessary.

Currently, as one of the low carbon sintering technology, attention has been paid to "Super Sinter," in which $\mathrm{CF}$ ratio is reported higher than the one in the conventional process ${ }^{24)}$ the mass ratio $Y=\mathrm{CF} /($ Iron oxides $+\mathrm{CF})=$ ca. 0.25 for conventional one, ${ }^{22)}$ while $Y=$ ca. 0.4 for "Super Sinter." The present model is effective as long as CF exists in sinter, while its necessity increases as the ratio of $\mathrm{CF}$ rises. In the case of the measured example shown in Section $3 \cdot 3$, the mass ratio of $\mathrm{Fe}_{2} \mathrm{O}_{3}$ in $\mathrm{CF}$ is $0.693,{ }^{22)}$ and therefore, the reducible oxygen ratio in $\mathrm{CF}$ becomes less than the value of $Y$. Still, it is easy to guess the occurrence of fatal error in the previous analyses, in which $\mathrm{CFw}$ was treated to be reducible in the thermal reserve zone irrespective of irreducible one there; the mass ratio of the irreducible oxygen is about 20 up to $30 \%$.

\section{Trial Comparison with Previous Experimental Data}

As explained in the former section, there are many future subjects to compute the reduction curves and others by using the present model. Especially, new experiments such as stepwise reduction experiments in six steps are needed to evaluate the rate parameter values of six $k_{\mathrm{c}}$ and six $D_{\mathrm{e}}$. In the present analysis, the present model calculation has been tried comparing with the previously reported experimental data $^{10)}$ by determining the rate parameter values of six $k_{\mathrm{c}}$ and six $D_{\mathrm{e}}$ by analogy from three $k_{\mathrm{c}}$ and three $D_{\mathrm{e}}$ values evaluated by using unreacted-core shrinking model for three interfaces.

In Fig. 1, the stepwise solid line for temperature vs. gas composition $^{10)}$ shows previously reported experimental conditions which simulated blast furnace conditions. ${ }^{5,6)}$ The simulated variation was only a stepwise line, which did not always agree well with the measured one, ${ }^{5,6)}$ but this is considered to meet the present goal to some extent, as far as the reduction reaction from ' $\mathrm{FeO}$ ' (or $\mathrm{CFW}$ in equations) to 'Fe' (or CFf in equations) is the focus of attention. In the experiment, fixed bed packed with Sinter B was reduced under up-rising temperature condition shown in Fig. 2 and synchronously stepwise rising gas concentration shown in Fig. 1.

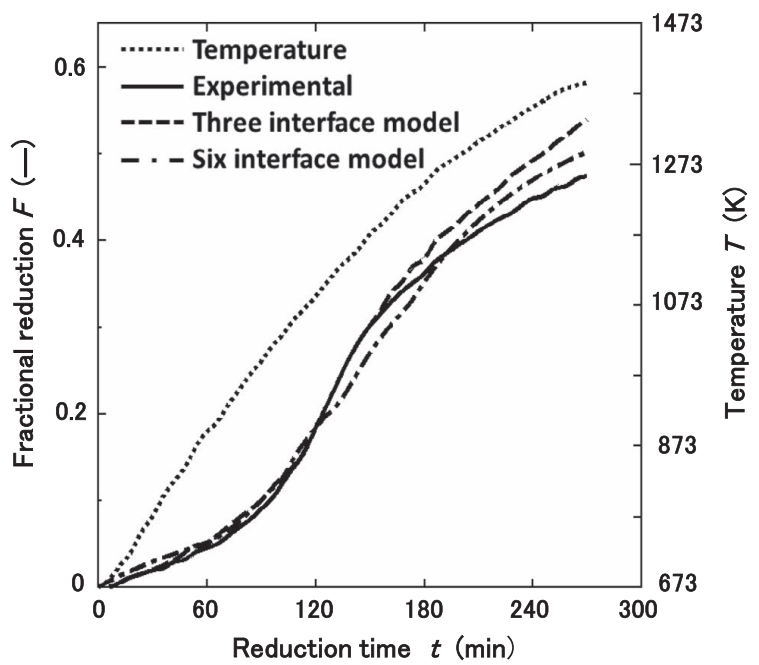

Fig. 2. Comparison between measured and calculated reduction curves under simulated blast furnace conditions which is shown in Fig. 1 as the stepwise solid line. ${ }^{10)}$ Total flow rate: $20 \mathrm{~L} / \mathrm{min}$ (s.t.p.), mole fraction of $\mathrm{N}_{2}=0.55(-)$ in $\mathrm{CO}-$ $\mathrm{CO}_{2}-\mathrm{N}_{2}$ gas mixture.

In the analysis, the rate parameter values of $\operatorname{six} k_{\mathrm{c}}$ and six $D_{\mathrm{e}}$ in the present model have been determined by analogy from three $k_{\mathrm{c}}$ and three $D_{\mathrm{e}}$ values for the unreacted-core shrinking model for three interfaces reported previously. ${ }^{10,15,16)}$ In the concrete, chemical reaction rate constants for Sinter $\mathrm{B},{ }^{10,15,16)} k_{\mathrm{C}}^{(\mathrm{h} / \mathrm{m})}, k_{\mathrm{C}}^{(\mathrm{m} / \mathrm{w})}$ and $k_{\mathrm{C}}^{(\mathrm{w} / \mathrm{Fe})}$ for the three interface model taking no account of $\mathrm{CF}$, are used to iron oxides as they are, while those for $\mathrm{CF}, k_{\mathrm{C}}^{(\mathrm{CFh} / \mathrm{CFm})}$, $k_{\mathrm{C}}^{(\mathrm{CFm} / \mathrm{CFw})}$ and $k_{\mathrm{C}}^{(\mathrm{CFw} / \mathrm{CFf})}$ are assumed to be half as large as those for the corresponding iron oxides. Similarly, intraparticle effective diffusivity $D_{\mathrm{e}}^{(\mathrm{m})}, D_{\mathrm{e}}^{(\mathrm{w})}$ and $D_{\mathrm{e}}^{(\mathrm{Fe})}$ are used as they are, as follows:

$$
D_{\mathrm{e}}^{(3)}=D_{\mathrm{e}}^{(\mathrm{m})}, \quad D_{\mathrm{e}}^{(5)}=D_{\mathrm{e}}^{(\mathrm{w})}, \quad D_{\mathrm{e}}^{(7)}=D_{\mathrm{e}}^{(\mathrm{Fe})}
$$

and as for $D_{\mathrm{e}}^{(2)}, D_{\mathrm{e}}^{(4)}$ and $D_{\mathrm{e}}^{(6)}$, the following relations are assumed:

$$
D_{\mathrm{e}}^{(2)}=D_{\mathrm{e}}^{(3)} / 2, \quad D_{\mathrm{e}}^{(4)}=D_{\mathrm{e}}^{(5)} / 2, \quad D_{\mathrm{e}}^{(6)}=D_{\mathrm{e}}^{(7)} / 2
$$

Qualitatively, these assumptions, 1/2, are considered significant, but it should be emphasized that these assumptions are only a baseless guess. Equilibrium constants $K$, chemical reaction rate constants $k_{\mathrm{C}}$ and intra-particle effective diffusivities $D_{\mathrm{e}}$ are given as functions of temperature and therefore they are easy to use under up-rising temperature condition.

Figure 2 shows comparison of reduction curves under up-rising temperature condition depicted by the stepwise solid line shown in Fig. 1 between calculated and measured ones. In the latter stage of reduction, the calculated reduction curve based on the present model agrees rather better with the experimental one than the calculated reduction curve based on the unreacted-core shrinking model for three interfaces reported previously. ${ }^{10)}$ Around the wustite/iron equilibrium, it can be considered to be reflected to some extent well that the reduction reaction from $\mathrm{CFw}$ to $\mathrm{CFf}$ does not proceede. 


\section{Conclusion}

Until now, the necessity to develop gaseous reduction model for sinter in consideration of calcium ferrite reduction has been emphasized. ${ }^{17,25,26)}$ Judging from the recent research activities such as Reducing agents minimization in a blast furnace ${ }^{3)}$ and Improvement of the iron ore sintering process aiming at lowering carbon, ${ }^{27}$ now is the time to develop such a model. Accordingly, the unreacted-core shrinking model for three interfaces has been expanded to the unreacted-core shrinking model for six interfaces in order to take calcium ferrite reduction process into consideration in the present work. It is obvious that the unreactedcore shrinking model cannot describe the reaction fashion of sinter, but this model is considered at least to be the first approximation and can be taken into account the most important point, namely, the incorporation of the reduction equilibrium gaps. In future subjects, it is necessary to obtain the rate parameter values by isothermal reduction experiments and to carry out up-rising temperature reduction experiments under the simulated variations of temperature and gas composition in a blast furnace.

After that, the effectiveness of the present model can be verified by comparing the calculated reduction curve with the experimental one under the simulated blast furnace conditions. In this work, the calculated reduction curve by the present model has been compared with the experimental one; the present one reproduces the experimental one rather better than the calculated reduction curve by the unreactedcore shrinking model for three interfaces.

The present model is expected to reproduce such an important phenomenon as no progress in the reduction reaction from $\mathrm{CFw}$ to $\mathrm{CFf}$, while slow progress in the reduction reaction from wustite to iron in the thermal reserve zone of a blast furnace. Therefore, more rational analysis can be done not only for the case of normal operation but also for the case of advanced operation such as the one aiming reduction of reducing agent by decreasing the thermal reserve zone temperature. The present model is effective as long as $\mathrm{CF}$ exists in sinter, while its necessity increases as the ratio of $\mathrm{CF}$ rises, depending on the sintering conditions, for example, "Super Sinter" process. ${ }^{24)}$

\section{Acknowledgments}

The authors wish to express our thanks to Mr. Kazuki Ohsawa, Mr. Takuya Okada and Mr. Ryo Sato, undergradu- ate students of Fukui University of Technology at the time of study, for their help. We are also grateful to Mr. Hirotoshi Kawabata, Graduate School of Engineering, Osaka University, for his cooperation in the reduction experiments and sample analyses quoted in this work. This work was supported in part by the Special Research Grants in 2010 and 2011 academic years from Fukui University of Technology.

\section{REFERENCES}

1) K. Sugiyama, A. Monkawa and T. Sugiyama: ISIJ Int., 45 (2005), 560 .

2) H. Ono-Nakazato, Y. Tsubone, Y. Takaki and T. Usui: Tetsu-toHagané, 87 (2001), 320.

3) Discussion Sessions of High Temperature Processes: CAMP-ISIJ, 23 (2010), 560, CD-ROM.

4) T. Usui and K. Higaki: CAMP-ISIJ, 7 (1994), 1027.

5) Y. Shimomura and T. Sugiyama: Private communication, (1982).

6) T. Sugiyama and M. Sugata: Seitetsu Kenkyu, (1987), No. 325, 34.

7) T. Usui, H. Kawabata, T. Fujimori, I. Fukuda and Z. Morita: Tetsuto-Hagané, 78 (1992), 982.

8) T. Maeda and Y. Ono: Tetsu-to-Hagané, 75 (1989), 416.

9) T. Maeda: Doctor Thesis, Kyushu University, (1992), 65.

10) T. Usui, M. Ohmi, M. Naito, H. Kamiya, Y. Oshima and Z. Morita: Proc. Julian Szekely Memorial Symp. on Materials Processing, ed. by H. Y. Sohn et al., TMS, Warredale, PA, (1997), 67.

11) M. Ohmi and T. Usui: Tetsu-to-Hagané, 59 (1973), 1888; Trans. Iron Steel Inst. Jpn., 16 (1976), 77.

12) R. H. Spitzer, F. S. Manning and W. O. Philbrook: Trans. Metall. Soc. AIME, 236 (1966), 1715.

13) Y. Hara, M. Tuchiya and S. Kondo: Tetsu-to-Hagané, 60 (1974), 1261.

14) M. Ohmi, M. Naito and T. Usui: Tech. Rep. Osaka Univ., 34 (1984), No.1743, 19 .

15) T. Usui, M. Ohmi, S. Hirashima and Y. Oshima: Proc. 5th Int. Iron and Steel Cong., Book 3, The Iron and Steel Society of AIME, Warrendale, PA, (1986), 545.

16) T. Usui, M. Ohmi, S. Kaneda, M. Ohmasa and Z. Morita: ISIJ Int., 31 (1991), 425.

17) T. Usui, M. Naito, T. Murayama and Z. Morita: Tetsu-to-Hagané, 80 (1994), 431.

18) T. Usui, Y. Nakamuro, M. Nishi, M. Naito, H. Ono and P. S. Assis: CAMP-ISIJ, 25 (2012), 603, CD-ROM.

19) M. Ohmi, T. Usui, M. Naito and Y. Minamide: Tetsu-to-Hagané, 67 (1981), 1943; Trans. Iron. Steel Inst. Jpn., 23 (1983), 81.

20) H. Hayashi, K. Inoue, K. Yoshioka and T. Takahashi: Tetsu-toHagané, 68 (1982), S738.

21) T. Usui, M. Ohmi, S. Hirashima and N. Kitagawa: Tetsu-to-Hagané, 73 (1987), 1956.

22) T. Usui, M. Ohmi, N. Kitagawa, S. Kaneda, H. Kawabata and Z. Morita: Tetsu-to-Hagané, 77 (1991), 1251.

23) T. Yagi and Y. Ono: Trans. Iron Steel Inst. Jpn., 8 (1968), 377.

24) N. Oyama, Y. Iwami, T. Yamamoto, S. Machida, T. Higuchi, H. Sato, M. Sato, K. Takeda, Y. Watanabe, M. Shimizu and K. Nishioka: Tetsu-to-Hagané, 97 (2011), 510; ISIJ Int., 51 (2011), 913.

25) T. Murayama, T. Usui, M. Naito and Y. Ono: Tetsu-to-Hagané, 80 (1994), 493

26) M. Naito, T. Murayama and T. Usui: Tetsu-to-Hagané, 80 (1994), 581.

27) Discussion Sessions of High Temperature Processes: CAMP-ISIJ, 25 (2012), 599, CD-ROM. 